\title{
Strategic Planning and Corporate Performance Relationship in Small Business Firms: Evidence from a Middle East Country Context
}

\author{
Jehad S. Aldehayyat (Corresponding author) \\ Department of Business Administration, College of Business and Economics \\ Al-Hussein Bin Talal University \\ PO Box 149, Ma'an, Jordan \\ Tel: 962-3-213-5516_E-mail: J.Aldehayyat@yahoo.co.uk \\ Naseem Twaissi \\ Department of Business Administration, College of Business and Economics \\ Al-Hussein Bin Talal University \\ Ma'an, Jordan \\ Tel: 962-777-836-895_E-mail: Naseem_Petra@hotmail.com
}

Received: February 10, 2011 Accepted: March 22, 2011 doi:10.5539/ijbm.v6n8p255

\begin{abstract}
This research aims to identify strategic planning system characteristics in Jordanian small industrial firms and to examine its relationship with corporate performance. This is one of the first studies to examine such questions. Existing literature, both theoretical and empirical, is examined to identify the state of knowledge associated with this question in both developed and middle East countries. The empirical research was co-ordinated via a survey of small Jordanian industrial publicly quoted firms. A questionnaire survey of these firms yielded a 52.1 per cent response rate. The results of the survey provided a rich source of data in relation to a variety of practices associated with strategic planning in small Jordanian industrial firms. Key findings provided empirical evidence about the involvement of top and line management in planning, the use of environmental screening, and the use of strategy tools and techniques. Furthermore, the study found a strong positive relationship between strategic planning and corporate performance. This research gives a new empirical evidence about the value of strategic planning to corporate performance from Middle East countries context.
\end{abstract}

Keywords: Strategic planning, Corporate performance, Jordan, Small firms

\section{Introduction}

Formal strategic planning is an explicit and ongoing organisational process that comprises of a number of components, such as the establishment of goals and the generation and evaluation of strategies (Boyd, 1991). The formal strategic planning process is analytical, systematic and deliberate. The benefits of strategic planning, as suggested in the literature (e.g. Greenley, 1986; Johnson and Scholes, 2002; Koufopolous and Morgan, 1994), can be summarised as: for enhancing co-ordination, (e.g. bringing together all business unit strategies within an overall corporate strategy); for controlling by reviewing performance and progress toward objectives; for identifying and exploiting future marketing opportunities; for enhancing internal communication between personnel; for encouraging personnel in a favourable attitude to change; for improving the corporate performance of companies. Some strategy scholars have claimed that formal strategic management procedures are particularly inappropriate for small firms because of their lack of management and financial resources (Govin and Slevin, 1989; Shrader et al., 1989). However, the results of empirical research (e.g. Baker et al., 1993; Berry, 1998; Peel and Pridge, 1998) have provided strong evidence that the number of small businesses which have adopted strategic planning is increasing over time because of their belief in its benefits especially in relation to the enhancement of corporate performance.

Most of studies regarding strategic planning in small businesses and its relationship with performance were carried out in the US and very few were undertaken in other developed countries such as the UK (e.g. Falshaw et al., 2006; Kraus; 2006; French et al., 2004; Griggs 2002; Berry, 1998; Peel and Pridge, 1998; Kargar and Parnell, 1996; Schwenk and Shrader 1993; Baker et al., 1993; Shuman et al., 1985; Robinson and Pearce 1984). Very little attention has been given to the study of strategic planning in small businesses in the Middle East context in general and in Jordan in particular. Although, Aldehayyat (2011), Elbanna (2007), Dincer, Tatoglu and Glaister (2006), Al-Shaikh (2001), Al-Shaikh and Hamami (1994), have studied strategic planning in a Middle East 
context, they did not give much attention to small firms. Also, none of them studied the effect of strategic planning on corporate performance. In fact only two empirical studies have been conducted to shed some light on such relationships in a Middle East context - Glaister et al. (2008) and Elbanna (2008) - but small firms were outside the scope of their research. Therefore, this research aims to fill the gap in the literature and provide new empirical evidence about strategic planning characteristics in Jordanian small business firms and to examine their relationship with corporate performance. This study is one of the first of its type in the Middle East context. The findings will be discussed in the light of the literature.

\section{Literature review}

\subsection{Strategic planning in small firms}

Berry (1998) argued that whether formal or informal strategic planning is carried out, managers should emphasize the substantive analytical elements of the process: scanning the environment; analysing competitive activity; assessing strengths and weaknesses; identifying and evaluating alternative courses of action; reviewing and revising plans. Welsh and White (1981) argued that small businesses should use the same management techniques as their larger counterparts. Indeed, studies indicate that increasing numbers of small businesses are adopting strategic planning because of its benefits (e.g. Baker et al., 1993; Berry, 1998). For instance, Peel and Pridge (1998) found that strategic planning is crucially important for performance enhancement in small and medium sized British manufacturing companies. In their meta-analysis Schwenk and Shrader (1993) reviewed twenty-six researches of small businesses. The study found a positive relationship between strategic planning and performance.

Berry (1998) studied the practice of strategic planning in small 'high tech' UK companies. The study found that most of these companies believe that strategic planning was either very important or essential. In terms of strategy, $80.67 \%$ had a long-term strategy developed in relation to products and markets. $38 \%$ indicated that these strategies were formal/ explicit, while $42 \%$ indicated that these strategies were informal/implicit. The author argued that the findings of this study supported the previous literature, which indicates the importance of strategic planning as a distinctive feature of successful management practice in small high tech firms.

Baker, Addams and Davis (1993) studied the practice of strategic planning in US small high growth firms. The study found that most of these companies perform strategic planning; $95 \%$ of the companies which perform strategic planning have a written plan. In terms of involvement of strategic planning, the CEOs are more frequently involved than any other person, followed by the vice president of marketing and the vice president of finance/accounting. The study also found that strategic planning has a positive influence on their companies.

Shuman and Sussman (1985) studied the practice of strategic planning in small rapid growth companies in the USA. The study found that, as the companies grew, planning became more formal and structured. However, the general findings resulting from this study were: the involvement of CEOs in the strategic planning process was more than the other managers' involvement and the absence of perceived benefits from strategic planning to the company influence negatively on the CEOs' attitudes toward planning.

\subsection{Strategic planning and performance relationship}

The prescriptive strategic management literature advocates that a positive relationship between strategic planning and financial performance (Glaister and Falshaw, 1999). However, the extent to which strategic planning contributes improvement of corporate performance is still a matter of controversy because of the mixed results which are found in empirical research. For instance, Schwenk and Shrader (1993) identified some reviews of the research on the effects of strategic planning on financial performance. Firstly, Armstrong (1982) reviewed twelve strategic planning and performance research. The study found that strategic planning cautiously benefited firms. Secondly, in a comprehensive review of over sixty studies Shrader, Mulford and Blackburn (1989) found no apparent systemic relationship between strategic planning and performance. Thirdly, a comprehensive review for small firms Robinson and Pearce (1984) indicated that the research on the value of strategic planning for small firms is not inconclusive because many small firms do not plan.

In their meta-analysis Schwenk and Shrader (1993) reviewed twenty-six researches of small businesses. The study found a positive relationship between strategic planning and performance. In another attempt, Greenley (1994) reviewed twenty-nine researches. The study found evidence that supported a relationship between strategic planning and financial performance. Miller and Cardinal (1994) reviewed twenty-six published researches. The study found strategic planning positively affected firm performance.

More recently, Kraus, Harms and Schwarz (2006) found that planning formalisation have positively effect on performance in small Austrian enterprise. While, Falshaw et al. (2006) found no relationship between formal planning process and company performance in UK companies. In contrast, Glaister et al. (2008) found strong positive relationship between formal planning process and performance in manufacturing Turkish companies. In the same vein, Elbanna (2008) emerged that strategic planning practice positively related to strategic planning effectiveness in privately owned Egyptian companies.

The possible reason for contradictory in the results reported in pervious studies is that the most of these studies 
analysed only one dimension of strategic planning, namely, formalisation. (Kraus et al., 2006; Lyles et al., 1993). The current study will adapt a multidimensional approach which developed by some strategy scholar to measure strategic planning in small business firms.

\subsection{Operationalising of strategic planning}

Griggs (2002) points out that empirical research in small firms normally employed unidimenitional measures such as the presence or absence of planning, its degree of formality, or the length of the planning horizon. Kargar and Parnell (1996) in his research on small banks and Griggs (2002) in his research on small-scale firms modified Ramanujam, Venkatraman and Camillus (1986) and Ramanujam and Venkatraman (1987) suggestion and used five strategic planning system characteristics: the use of strategy tools and techniques, attention to internal facets, attention to external facets, functional coverage and involvement of key personnel in the planning process. Following these studies, five dimensions were adopted to study strategic planning process (Table 1).

$$
\text { Table } 1 \text { - about here }
$$

\section{Methodology}

\subsection{Research population and respondents}

The research population is the body of people, organisations, or any other collection of items under consideration for a research purpose (Hussey and Hussey, 1997). The population of this research is defined as all 105 small industrial firms that are registered on the Amman Stock Exchange (ASE).

The rationale for choosing the companies listed in ASE is due to of the absence of database for the companies that are not classified in this market. The data collection instrument was sent to the whole population in view of its size. One hundred and fifteen questionnaires were distributed and a total of sixty valid responses rate were received for conducting the research data analyses. The response rate was $(52.1 \%)$, which is considered a good rate compared with the other studies in the same area. The Chi-square test was performed to determine whether there was a significant difference between the respondents and the population. The results indicate no significant difference between respondents and the population $\left(\chi^{2}=3.282, \mathrm{df}=2, p=194\right)$. Thus, the results of this test indicate that the characteristics of the respondents are similar to the characteristics of population.

\subsection{Characteristics of Respondents}

Table 2 summaries the respondents' characteristics

Table 2 - about here

\subsection{Measures}

For the measure of strategic planning, multidimensional approach was adapted which suggested by Ramanujam et al. (1986), Ramanujam and Venkatraman (1987) and modified by Kargar and Parnell (1996) and Griggs (2002). Thus, the final questionnaire consists of four items related to corporate performance and thirty four items related to strategic planning belonging to five sets of questions. The first set of questions involves the attention to internal and external aspects. Respondents were asked, on a five-point scale rating from "significantly less emphasise" to " significantly more emphasise", to indicate to the degree of emphasis placed on each of the nine environmental scanning, internal (Gronbach alpha $=0.7321$ ), and external (Gronbach alpha $=0.7551$ ), areas. The second set of questions involves the use of strategy techniques. Respondents were asked, on a five-point scale rating from "not important" to "very important", to indicate to the degree of importance of the eight techniques to their strategic planning (Gronbach alpha $=0.8272$ ). The third set of questions involves the functional coverage. Respondents were asked, on a five-point scale rating from "significantly less emphasise" to "significantly more emphasise", to indicate to the degree of emphasis placed on each of the seven functional areas (Gronbach alpha $=0.8545)$. The fourth and fifth sets of questions examine the participation of top and line managers in strategy. In fourth sets of questions the respondents were asked, on a scale rating from" not participating at all" to "strongly participating", to indicate the degree of participation of top management in strategic activities in four areas (Gronbach alpha $=0.7515)$. In fifth sets of questions the respondents were asked, on a scale rating from "not participating at all" to "strongly participating" to indicate the degree of participation of top management in strategic activities in four areas (Gronbach alpha $=0.7948$ ). The measurement scale of participation of top and line managers in strategy was adopted from Yasai-Ardekani and Haug (1997).

The subjective corporate performance was measured by asking the respondents, on a five-point scale to indicate to their corporate performance compared with that of their major competitors in relation to competitive position, efficiency of operations, return on assets, growth rate, and overall financial performance for the previous three years. These measures were first used by Dess and Robinson (1984) and subsequently by other strategy researchers.

\section{Data analysis}

Table 3 shows that the most significant issues regarding environmental scanning are World-wide competitive trends, then technological trends, followed by internal capabilities and, in fourth place, general economic and business conditions. The least significant issues for them are the past performance and the reasons for past 
failures.

Table 3 shows that the most used technique is financial analysis. This is followed by using PEST or STEP analysis, Porter's five-forces analysis and analysis of key (critical) success factors. The results indicate to a relatively less focus on the use of internal analysis techniques, such as core capability/ competence analysis, human resource analysis and value chain analysis. Table 4 shows little use of analysis of organisational culture and a little focus on the use of scenario construction by these companies.

Regarding the functional converges of strategic planning, Table 3 shows that higher mean scores is for finance and marketing computing followed by management information system, function. The lower mean score is for research and development and technology.

Table 3 shows the strongest participation by top management is in choosing strategic proposals, then on consideration and elaboration of strategic issues, followed by the generation of strategic proposals and, in last place, they participate in the evaluation of strategic proposals. However, the results indicate that the mean for all items is over 3, which indicates a relatively high participation in all strategic planning activities by top management.

Table 3 shows that the strongest participation by line management is on consideration and elaboration of strategic issues, then on generation of strategic proposals, followed by their participation in the evaluation of strategic proposals and, in the last place, their participation in choosing strategic proposals. However, the results indicate that the mean for all items is more than 3 except one item, namely, choosing a strategic proposal which indicates a relatively high level of participation in strategic activities.

Table 3 - about here

Spearman's correlation was conducted to assess the relationships between the strategic planning and corporate performance. The results of the test in Table 4 shows that there is a strong positive significant relationship between strategic planning and corporate performance in Jordanian small firms (correlation .858 at .01 level). Also, all dimensions of strategic planning had significant relationship with corporate performance as following: environment scanning (correlation .463 at .01 level), use of strategy techniques (correlation .530 at .01 level), functional coverage (correlation .664 at .01 level), top management involvement (correlation .668 at .01 level), line management involvement (correlation .664 at .01 level).

Table 4 - about here

\section{Discussion of the Findings}

The research findings show that these companies give less importance to internal scanning than external scanning. The findings show that the analysis of world-wide competitive trends is related to smaller companies. The possible explanation for this result is that many of the small industrial firms in the last few years exported their production to the USA, Europe and other Arab countries. The importance of the external environment to these firms could be affected by a number of factors which face small Jordanian firms such as the level of technological development, entrance to new markets in USA, Europe as well as Arab countries and the numerous new laws and increases in the number of international investors in Jordan recently

The findings show that there is relatively little focuses on the use of strategy techniques as the mean is less than 3. However, the findings indicate that the most used technique is financial analysis for own business. It seems that the use of financial techniques is popular among firms in many countries (Aldehayyat and Anchor, 2008). Also, the research findings indicate that techniques, such as PEST or STEP analysis, Porter's five-forces analysis and analysis of key (critical) success factors received a high ranking among other techniques which reflects the interest in external analyses by these companies. These findings are related to the earlier results which indicate that these firms have relatively more interest in external issues.

On the other hand, these findings show relatively less focus on the use of internal analysis techniques such as core capability/ competence analysis, human resource analysis and value chain analysis. Also, the findings show little use of portfolio analysis, strategic planning software and experience curve analysis. The findings indicate that firms do not undertake the analysis of organisational culture, although strategy formulation and implementation were strongly affected by the culture of an organisation (Aldehayyat and Anchor, 2008).

The research findings indicate that these firms have little focus on the use of scenario construction by. Although, the use of this technique has its benefits such as: providing these firms with an approach to flexible planning by developing several alternative views of the future (Phelps et al., 2001). In addition, it helps to prepare managers to face uncertainty and an unpredictable future environment.

In general, the strategic plan covers most of these firms function, mean 3 and above. However it is worthwhile to notice that the lack of interest in the most important function namely, research and development and technology which mean that they depend on the foreign research and technology. However, the average spend on the research and development in developing countries is too much less than that in developing countries.

The research findings indicate a relatively high participation by top management in all strategic planning activities. These results are consistent with the literature regarding the importance of the top management role in 
the strategic planning process (Aldehayyat, 2006; Koufopoulos and Morgan, 1994; Athiyaman and Robertson, 1995). These results support the view which emphasised the critical role of the entrepreneur in determining the strategic orientation and planning practices of small business (Berry, 1998).

The research findings shows that the mean for all areas of strategic planning is more than three in the case of line management, except in choosing strategic proposals, which indicates a high level of participation in strategic activities. However, choosing strategic proposals comes last in the ranking which indicates that middle management in these firms participate in strategic activities but with less participation in choosing a strategic proposal, which is related more to top management in these firms. The decentralisation of the strategy making process to include line managers is considered to be one of the important changes that characterised strategic planning recently (Aldehayyat, 2006; Bonn and Christodoulou, 1996). The results indicate a good degree of involvement by line managers in these companies in the strategic planning process

The research finding shows all strategic planning dimensions and overall strategic planning had a significant relationship with corporate performance. This result strongly supports the empirical research which indicate to the value of strategic planning to the corporate performance. Thus, it is not surprising that these firms paid much effort to involve themselves in strategic planning process (see the above results regarding strategic planning dimensions) since they believe in its benefits to corporate performance.

\section{Conclusions}

The results of this research strongly support prescriptive strategic management literature which advocates that a positive relationship between strategic planning and financial performance (e.g. Glaister and Falshaw, 1999). Moreover, this research give a new evidence about the practice of strategic planning in small business firms and thus, support the results of empirical research (e.g. Baker et al., 1993; Berry, 1998; Peel and Pridge, 1998) which stated that the number of small businesses which have adopted strategic planning is increasing over time because of their belief in its benefits especially in relation to the enhancement of corporate performance.

The study presented a new evidence to explain the nature of strategic planning in small firms and its relationship with performance in non-developed country context. Besides, it provides empirical evidence of some important areas of strategic planning practice in small firms including: the nature of involvement of top and line management in planning activities, the use of environmental scanning (internal and external), and the use of strategy tools/ techniques. Moreover, this study is one of the first attempts to provide an insight into better understanding the nature and practices of strategic planning in small firms in Middle East countries in general and in Jordan in particular

Although the results of this research provide an empirical evidence about the nature of the relationship between strategic planning characteristics and corporate performance in a non- developed countries context, it is important to clarify some of its limitations: because this research was limited to publicly quoted industrial firms, the results may not generalisable to other industry settings. The data obtained for variables were self reported rather than obtained from independent source. This research focused on what and how questions and did not explore why, via face to face interview or focus groups.

Control the contingency factors such as firm size, industry and environmental are considered as important in strategy research, studying of these factors were out scope of this research. However, control these factors with the relationship between strategic planning and corporate performance could be the further area of research in the case of small business firms in Middle East context.

\section{References}

Aldehayyat, J. (2006). Strategic Planning in Publicly quoted Jordanian Companies, Ph.D. Thesis, University of Huddersfield.

Aldehayyat, J. (2011). Organisational characteristics and the practice of strategic planning in Jordanian hotels. International Journal of Hospitality management, 30 (1), 192-199.

Aldehayyat, J., and Anchor, J. (2008). Strategic planning tools and techniques in Jordan: awareness and use. Strategic Change, 17 (7/8), 281-293.

Al-Shaikh, F. (2001). Strategic planning process in developed countries: the case of United Arab Emirates business firms. Management Research News, 21 (12), 7-16.

Al-Shaikh, F., and Hamami, Y. (1994). Strategic planning in Jordan business organisations. International Journal of Management, 11 (4), 982-939.

Armstrong, J. (1982). The value of formal planning for strategic decisions: review of empirical research. Strategic Management Journal, 3 (3), 197-211.

Athiyaman, A., and Robertson, R. (1995). Strategic planning in large tourism firms: an empirical analysis. Tourism Management, 16 (3), 199-205.

Baker, W., Addams, H., and Davis, B. (1993). Business planning in successful small firms. Long Range Planning, 26 (6), 82-88. 
Berry, M. (1998). Strategic planning in small high tech companies. Long Range Planning, 31 (3), 455-466.

Bonn, I., and Christodoulou, C. (1996). From strategic planning to strategic management. Long Range Planning, 24 (4), 543-551.

Boyd, B. (1991). Strategic planning and financial performance: a meta analysis review. Journal of Management Studies, 28 (40), 353-374.

Dess, GG., and Robinson, R. (1984). Measuring organisational performance in the absence of objective measures: the case of privately-held firm and conglomerate business unit. Strategic Management Journal, 5 (3), 265-73.

Dincer, O., Tatoglu, E., and Glaister, K. (2006). The strategic planning process: evidence from Turkish firm. Management Research News, 29 (4), 206-219.

Elbanna S. (2007). The nature and practice of strategic planning in Egypt. Strategic Change, 16 (5), 227-243.

Elbanna, S. (2008). Planning and participation as determinants of strategic planning effectiveness evidence from the Arabic context. Management Decision, 46 (5), 779-796.

Falshaw, J., Glaister, K., and Tatoglue, E. (2006). Evidence on formal strategic planning and company performance. Management Decision, 44 (1), 9-30.

French, S., Kelly, S., and Harrison, J. (2004). The role of strategic planning in the performance of small, professional service firms. Journal of Management Development, 23 (8), 765-776.

Glaister, K, Dincer, O., Tatoglo, E., Demirbag, M., and Zaim, S. (2008). A causal analysis of formal strategic planning and firm performance evidence from an emerging country. Management Decision, 46 (3), 365-391.

Glaister, K., and Falshaw, R. (1999). Strategic planning: still going strong? Long Range Planning, 32 (1), 107-116.

Govin, J., and Slevin, D. (1989). Strategic management of small firms in hostile and benign environments. Strategic Management Journal, 10 (1), 75-87.

Greenley, E. (1986). Does strategic planning improve company performance? Long Range Planning, 19 (2), 101-108.

Greenley, G. (1994). Strategic planning and company performance: an appraisal of empirical evidence. Scandinavian Journal of management, 10 (4), 383-396.

Griggs, H. (2002). Strategic planning system chrematistics and organisational effectiveness in Australian small-scale firms. The Irish Journal of Management, 23 (1), 23-53.

Hussey, J., and Hussey, R. (1997). Business Research. Hampshire: Palgrave.

Johnson, G., and Scholes, K. (2002). Exploring Corporate Strategy. Harlow: Financial Times Prentice Hall.

Karger, J., and Parnell, J. (1996). Strategic planning emphasis and planning satisfaction in small firms: an empirical investigation. Journal of Business Strategy, 13 (1), 42-64.

Koufopoulos, D., and Morgan, N. (1994). Competitive pressures force Greek entrepreneurs to plan. Long Range Planning, 27 (4), 112-124.

Kraus, S., Harms, R., and Schwarz, E. (2006). Strategic planning in smaller enterprises-new empirical findings. Management Research News, 29 (6), 334-344.

Lyles, M., Baird, I., Orris, J., and Kuratko, D. (1993). Formalized planning in small business: increasing strategic choices. Journal of Small Business Management, 31 (2), 38-50.

Miller, C., and Cardinal, L. (1994). Strategic planning and firm performance: a synthesis of two decades of research. Academy of Management Journal, 37 (6), 1649-1665.

Peel, M., and Bridge, J. (1998). How planning and capital budgeting improve SME performance. Long Range Planning, 31 (6), 848-856.

Phelps, R., Chan, C., and Kapsalis, S. (2001). Does scenario planning affect performance? Two exploratory studies. Journal of Business Research, 51 (3), 223-232.

Ramanujam, V., and Venkatraman, N. (1987). Planning system characteristics and planning effectiveness. Strategic Management Journal, 8 (5), 453-468.

Ramanujam, V., Venkatraman, N., and Camillus, J. (1986). Multi-objective assessment of effectiveness of strategic planning a discriminate analysis approach. Academy of Management Review, 29 (2), 347-372.

Robinson, R., and Pearce, J. 1984. Research thrusts in small firm strategic planning. Academy of Management Review, 9 (1), 128-137.

Schwenk, C., and Schrader, C. (1993). Effects of formal planning on financial performance in small firms: a meta-analysis. Entrepreneurship Theory and Practice, 17 (3), 53-63.

Shrader, C, Mulford, C., and Blackburn, V. (1989). Strategic and operational planning, uncertainty, and 
performance in small firms. Journal of Small Business Management, 27 (4), 45-60.

Shuman, J., Shaw, J., and Sussman, B. (1985). Strategic planning in smaller rapid growth companies. Long Range Planning, 18 (6), 48-53.

Walash, J., and White, J. (1981). A small is not a little big business. Harvard Business review, July-August, 18-32.

Yasai-Ardekania, M., and Haug, R. (1997). Contextual determinations of strategic planning process. Journal of Management Studies, 34 (5), 729-767.

Table 1. Characteristics of strategic planning system

\begin{tabular}{|l|l|}
\hline Dimensions & Description \\
\hline Attention to internal aspects & $\begin{array}{l}\text { The degree of attention given to past performance and analysis of } \\
\text { strength and weakness }\end{array}$ \\
Use of techniques & $\begin{array}{l}\text { The attention given to monitoring environmental trends } \\
\text { The degree of attention paced on strategic technique to structure } \\
\text { ill-defined strategic problems }\end{array}$ \\
Functional coverage & $\begin{array}{l}\text { The extent of converge given to different functional areas with a } \\
\text { view to integrating different functional requirement into a } \\
\text { general management perspective }\end{array}$ \\
Involvement of key personnel & $\begin{array}{l}\text { The degree of involvement of top and line management in strategic } \\
\text { planning process }\end{array}$ \\
\hline
\end{tabular}

Table 2. Characteristics of respondents

\begin{tabular}{|l|l|l|}
\hline Characteristics & Freq. & \% \\
\hline Age & & \\
Under 30 & 8 & 13.3 \\
$30-40$ & 16 & 26.7 \\
$41-50$ & 18 & 30 \\
$51-60$ & 10 & 16.7 \\
$61-$-over & 8 & 13.3 \\
Gender & & \\
Male & 56 & 93.3 \\
Female & 4 & 6.7 \\
Education level & & \\
College degree & 8 & 13.3 \\
Bachelor's degree & 38 & 63.3 \\
Postgraduate degree & 10 & 16.7 \\
Others & 4 & 6.7 \\
Experience in current position & & \\
Under 5 years & 13 & 21.7 \\
5-10 & 14 & 23.3 \\
$11-15$ & 12 & 20 \\
$16-20$ & 13 & 21.7 \\
$21-$-over & 8 & 13.3 \\
Total working experience & & \\
Under 5 years & 3 & 5 \\
$5-10$ & 16 & 26.7 \\
$11-15$ & 12 & 20 \\
$16-20$ & 14 & 23.3 \\
$21-$-over & 15 & 25 \\
\hline
\end{tabular}


Table 3. Descriptive Statistics for each strategic planning characteristic

\begin{tabular}{|l|l|l|}
\hline Strategic planning characteristics & Mean & SD \\
\hline Environmental scanning & \multicolumn{2}{|l|}{} \\
\hline Internal capabilities & 3.500 & 1.572 \\
Past performance & 2.571 & 1.358 \\
Reason for past failures & 2.324 & 1.306 \\
General economic and business conditions & 3.443 & 1.161 \\
Regulatory issues & 3.357 & 1.104 \\
Supplier trends & 2.607 & 1.286 \\
World-wide competitive trends & 3.785 & 1.130 \\
Customer/end user trends & 2.892 & 1.030 \\
Technological trends & 3.700 & .9946 \\
\hline Use of strategy techniques & \multicolumn{2}{|l|}{} \\
\hline Porter's five-forces analysis & 2.800 & .9976 \\
Financial analysis & 3.000 & 1.396 \\
Value chain analysis & 2.700 & .9560 \\
Portfolio analysis (e.g. BCG: growth- share) & 2.721 & 1.098 \\
Core capability/ competence analysis & 2.701 & 1.181 \\
Scenario construction & 1.980 & 1.334 \\
Human resource analysis & 2.231 & 1.490 \\
Analysis of organisational culture & 2.000 & 1.032 \\
PEST or STEP analysis & 2.980 & .8871 \\
Analysis of key (critical) success factors & 2.780 & 1.373 \\
\hline Functional converge & \multicolumn{2}{|l|}{} \\
\hline Marketing function & 3.000 & 1.400 \\
Operations/manufacturing functions & 3.321 & 1.334 \\
Finance functions & 3.844 & 1.121 \\
Personnel functions & 3.071 & 1.245 \\
Purchasing function & 2.912 & 1.214 \\
Research and development and technology & 2.234 & 1.370 \\
Computing and management information system & 3.614 & .8095 \\
\hline Top management participation in strategic planning & \multicolumn{2}{|l}{} \\
\hline Consideration and elaboration of strategic issues & 3.78 & 1.052 \\
Generation of strategic proposals & 3.65 & 1.214 \\
Evaluation of strategic proposals & 3.62 & .7704 \\
Choosing strategic proposals & 3.96 & .8095 \\
\hline Line management participation in strategic planning & \multicolumn{2}{|l|}{} \\
\hline Consideration and elaboration of strategic issues & 3.45 & .9052 \\
Generation of strategic proposals & 3.30 & 1.214 \\
Evaluation of strategic proposals & 3.22 & .8703 \\
Choosing strategic proposals & 2.69 & 1.321 \\
\hline & \multicolumn{2}{|l}{} \\
\hline
\end{tabular}


Table 4. The correlation between strategic planning characteristics and corporate performance

\begin{tabular}{|c|c|c|c|c|c|c|c|c|}
\hline & & \begin{tabular}{|l|} 
Strategic \\
planning
\end{tabular} & $\begin{array}{c}\text { Environment } \\
\text { scanning }\end{array}$ & \begin{tabular}{|c|} 
Strategy \\
techniques
\end{tabular} & $\begin{array}{c}\text { Functional } \\
\text { coverage }\end{array}$ & \begin{tabular}{|c|} 
Involvment of \\
top manag.
\end{tabular} & $\begin{array}{l}\text { Involvment of } \\
\text { line manag. }\end{array}$ & \begin{tabular}{|c|} 
Corporate \\
performance \\
\end{tabular} \\
\hline \multirow[t]{3}{*}{ Strategic planning } & Correlation Coeffici & 1.000 & $.809^{*}$ & $.678^{*+1}$ & $.744^{\star *}$ & $.843^{*}$ & $.747^{* * 1}$ & $.858^{*}$ \\
\hline & Sig. (1-tailed) & & .000 & .000 & .000 & .000 & .000 & .000 \\
\hline & $\mathrm{N}$ & 60 & 60 & 60 & 60 & 60 & 59 & 60 \\
\hline \multirow[t]{3}{*}{ Environment scanning } & Correlation Coeffici & $.809^{*}$ & 1.000 & $.422^{*}$ & $.621^{* *}$ & $.694^{* *}$ & $.479^{* *}$ & $.463^{*}$ \\
\hline & Sig. (1-tailed) & .000 & & .013 & .000 & .000 & .005 & .007 \\
\hline & $\mathrm{N}$ & 60 & 59 & 60 & 59 & 60 & 60 & 60 \\
\hline \multirow[t]{3}{*}{ Strategy techniques } & Correlation Coeffici & $.678^{*}$ & $.422^{*}$ & 1.000 & $.328^{*}$ & $.434^{*}$ & $.625^{* *}$ & $.530^{*}$ \\
\hline & Sig. (1-tailed) & .000 & .013 & . & .044 & .012 & .000 & .002 \\
\hline & $\mathrm{N}$ & 60 & 60 & 60 & 60 & 59 & 60 & 60 \\
\hline \multirow[t]{2}{*}{ Functional coverage } & Correlation Coeffici & $.744^{*}$ & $.621^{*}$ & $.328^{*}$ & 1.000 & $.703^{*}$ & $.567^{\star *}$ & $.664^{*}$ \\
\hline & Sig. (1-tailed) & .000 & .000 & .044 & . & .000 & .001 & .000 \\
\hline & $\mathrm{N}$ & 60 & 60 & 60 & 60 & 60 & 60 & 60 \\
\hline \multirow{3}{*}{ Involvment of top man } & Correlation Coeffici & $.843^{*}$ & $.694^{*}$ & $.434^{*}$ & $.703^{\star \prime}$ & 1.000 & $.524^{\star 1}$ & $.688^{*}$ \\
\hline & Sig. (1-tailed) & .000 & .000 & .012 & .000 & & .003 & .000 \\
\hline & $\mathrm{N}$ & 60 & 60 & 60 & 60 & 60 & 60 & 60 \\
\hline \multirow[t]{3}{*}{ Involvment of line mar } & Correlation Coeffici & $.747^{*}$ & $.479^{*}$ & $.625^{*}$ & $.567^{* 1}$ & $.524^{*}$ & 1.000 & $.664 *$ \\
\hline & Sig. (1-tailed) & .000 & .005 & .000 & .001 & .003 & . & .000 \\
\hline & $\mathrm{N}$ & 60 & 60 & 60 & 60 & 60 & 60 & 60 \\
\hline \multirow[t]{3}{*}{ Corporate performanc } & Correlation Coeffici & $.858^{*}$ & $.463^{\star}$ & $.530 *$ & $.664^{* *}$ & $.688^{*}$ & $.664^{* *}$ & 1.000 \\
\hline & Sig. (1-tailed) & .000 & .007 & .002 & .000 & .000 & .000 & \\
\hline & $\mathrm{N}$ & 60 & 59 & 60 & 60 & 60 & 60 & 60 \\
\hline
\end{tabular}

${ }^{* *}$. Correlation is significant at the .01 level (1-tailed).

${ }^{*}$. Correlation is significant at the .05 level (1-tailed). 